\title{
BMC
}

Research Notes

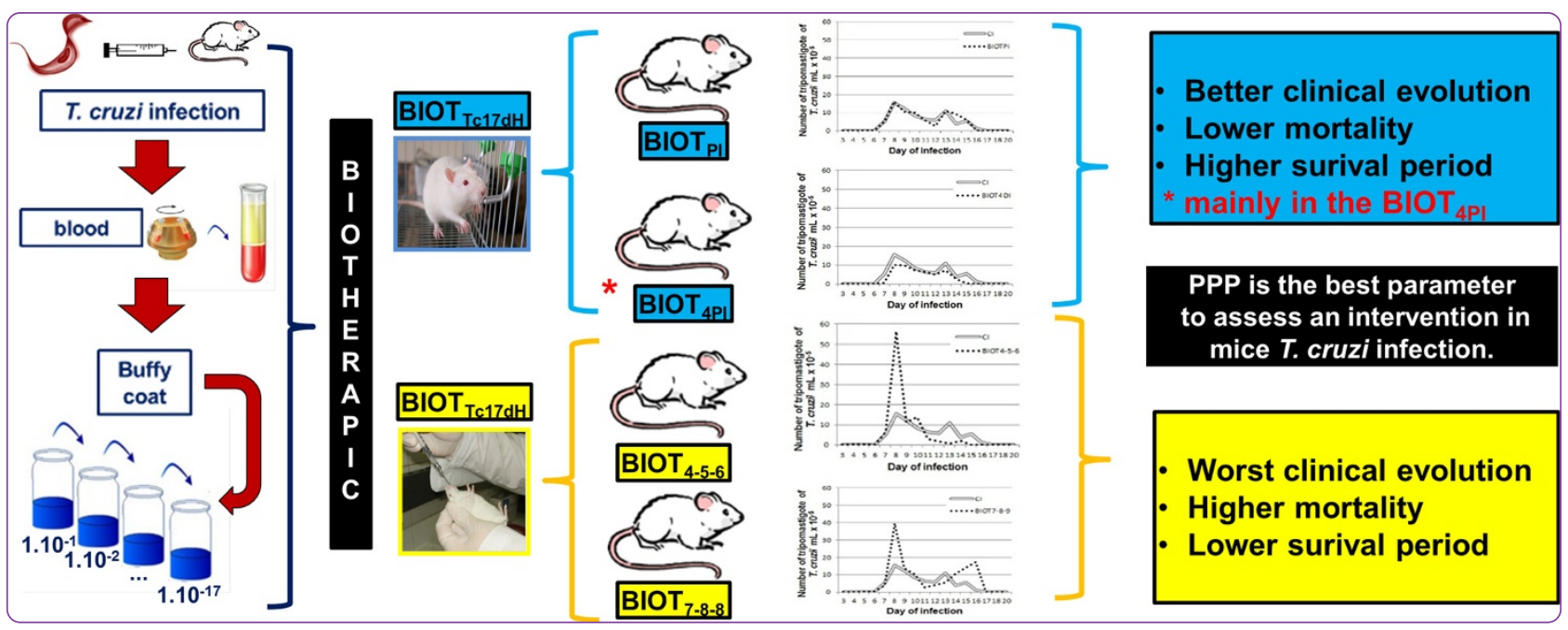

\section{Highly diluted medication reduces parasitemia and improves experimental infection evolution by Trypanosoma cruzi}

Aleixo et al. 


\title{
Highly diluted medication reduces parasitemia and improves experimental infection evolution by Trypanosoma cruzi
}

Denise Lessa Aleixo ${ }^{1 *}$, Fabiana Nabarro Ferraz ${ }^{1}$, Érika Cristina Ferreira ${ }^{1}$, Marta de Lana², Mônica Lúcia Gomes ${ }^{1}$, Benício Alves de Abreu Filho ${ }^{3}$ and Silvana Marques de Araújo ${ }^{1}$

\author{
Abstract \\ Background: There is no published information about the use of different protocols to administer a highly \\ diluted medication. \\ Evaluate the effect of different protocols for treatment with biotherapic T. cruzi $17 \mathrm{dH}$ (BIOT $\left.T_{\mathrm{Tc} 17 \mathrm{dH}}\right)$ on \\ clinical/parasitological evolution of mice infected with T. cruzi-Y strain.
}

Methods: A blind, randomized controlled trial was performed twice, using 60 28-day-old male Swiss mice infected with T. cruzi-Y strain, in five treatment groups: $\mathrm{Cl}$ - treated with a $7 \%$ ethanol-water solution, diluted in water $(10 \mu \mathrm{L} / \mathrm{mL})$ ad libitum; $B I O T_{P I}$ - treated with $\mathrm{BIOT}_{T \mathrm{C} 17 \mathrm{dH}}$ in water $(10 \mu \mathrm{L} / \mathrm{mL})$ ad libitum during a period that started on the day of infection; BIOT $4 \mathrm{DI}$ - treated with $\mathrm{BIOT}_{T \mathrm{C} 17 \mathrm{dH}}$ in water $(10 \mu \mathrm{L} / \mathrm{mL})$ ad libitum beginning on the $4^{\text {th }}$ day of infection; BIOT ${ }_{4-5-6}$ - treated with $\mathrm{BIOT}_{T \mathrm{~T} 17 \mathrm{dH}}$ by gavage $\left(0.2 \mathrm{~mL} /\right.$ animal/day) on the $4^{\text {th }}, 5^{\text {th }}$ and $6^{\text {th }}$ days after infection; $B / O T_{7-8-9}$ - treated with $\mathrm{BIOT}_{T \mathrm{~T} 17 \mathrm{dH}}$ by gavage $\left(0.2 \mathrm{~mL} /\right.$ animal/day) on the $7^{\text {th }}, 8^{\text {th }}$ and $9^{\text {th }}$ days after infection. We evaluated: parasitemia; total parasitemia $\left(P_{\text {total }}\right)$; maximum peak of parasites; prepatent period (PPP) - time from infection to detection of the parasite in blood; patent period (PP) - period when the parasitemia can be detected in blood; clinical aspects; and mortality.

Results: Parasitological parameters in the BIOT and mainly in the BIOT 4 PI group showed better evolution of the

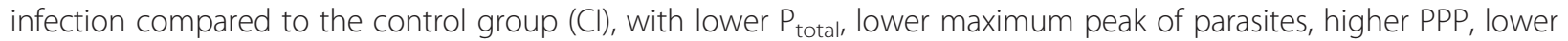
PP and longer survival times. These animals showed stable body temperature and higher weight gain and water consumption, with more animals having normal-appearing fur for longer periods. In contrast, groups $\mathrm{BIOT}_{4-5-6}$ and $\mathrm{BIOT}_{7-8-9}$ showed worse evolution of the infection compared to the control group, considering both parasitological and clinical parameters. The correlation analysis combined with the other data from this study indicated that the prepatent period is the best parameter to evaluate the effect of a medication in this model.

Conclusions: The $\mathrm{BIOT}_{4 \mathrm{DI}}$ group showed the best clinical and parasitological evolution, with lower parasitemia and a trend toward lower mortality and a longer survival period. The prepatent period was the best parameter to evaluate the effect of a medication in this model.

Keywords: Biotherapy, Mice infection, Parasitological evaluation, Clinical evaluation, Prepatent period

\footnotetext{
* Correspondence: deniseparasito@gmail.com

'Laboratory of Parasitology, Universidade Estadual de Maringá, Maringá, PR, Brazil

Full list of author information is available at the end of the article
}

\section{Ciomed Central}

(c) 2012 Aleixo et al.; licensee BioMed Central Ltd. This is an Open Access article distributed under the terms of the Creative Commons Attribution License (http://creativecommons.org/licenses/by/2.0), which permits unrestricted use, distribution, and reproduction in any medium, provided the original work is properly cited. 


\section{Background}

The use of highly diluted medications in the treatment of parasitic diseases has been investigated, but the available information does not allow us to demonstrate details of their effects. One of the hypotheses regarding the therapeutic effect of these drugs is that they modulate the immune system, and understanding the dynamics of this effect depends on the recognition of the information systems involved [1,2]. Bellavite et al. (2007) [3] suggested that homeopathic medicine can regulate inflammatory and immunopathological processes as well as the neuroendocrine network and peripheral receptors. Specifically in mice infected with $T$. cruzi, one study reported an increase in the apoptosis rate and a decrease in the secretion of TGF- $\beta$ measured in serum collected from the group treated with biotherapic medication, compared with the control group [4].

Although several studies have attempted to explain the clinical results of highly diluted medications, few trials have evaluated the effect of different treatment schemes with these drugs on living organisms [5-7].

Biotherapics are highly diluted medications prepared according to homeopathic techniques [8] from biological products, including the etiological agent itself [9]. Although experience in clinical practice using biotherapics cannot be ignored, academic research on biotherapics has been questioned [10].

Chagas disease, caused by the protozoan Trypanosoma cruzi, has been studied for more than a century. However, no effective drug for etiological treatment has been discovered so far [11].

T. cruzi-Y is considered a reference strain [12]. Extensively studied in experimental murine models, it shows well-defined characteristics such as high parasitemia, peak of parasites by the $12^{\text {th }}$ day of infection, death of all untreated infected animals, and partial resistance to drugs classically used in the treatment of human Chagas disease. Therefore, the murine model is an excellent experimental model for the evaluation of drug interventions [13].

According to the literature, morbidity is related to the presence of the parasite $[14,15]$, and pathogenesis increase is the result of a disruption of the host-parasite relationship [16]. Therefore, using biotherapics as an intervention in murine infection with $T$. cruzi is a possible means to understand the effect of these highly diluted medications and to find new candidates to treat Chagas disease.

The present study evaluated in vivo the effect of different treatment schemes using the biotherapic Trypanosoma cruzi $17 \mathrm{dH}\left(\mathrm{BIOT}_{T c 17 \mathrm{dH}}\right)$ in an experimental infection by this protozoan.

\section{Results and discussion}

As far as we are aware, this is the first study to compare different treatment schemes using a biotherapic $T$. cruzi in murine infection by the protozoan. Evaluation of parasitological and clinical parameters showed that the different treatment schemes using this medicine produced different profiles in the evolution of the infection of the $\mathrm{Y}$ strain of T. cruzi in Swiss mice.

\section{Parasitological parameters}

The mean and standard deviation of the parasitological parameters for each group are shown in Tables 1 and 2 . The evolution of parasitemia in groups of animals treated with biotherapics diluted in water ad libitum for a long period $\left(\mathrm{BIOT}_{\mathrm{PI}}\right.$ and $\mathrm{BIOT}_{4 \mathrm{PI}}$ ) showed better evolution of the infection compared to the control group (CI).

Compared to the control group, animals treated with $\mathrm{BIOT}_{\mathrm{PI}}$ and mainly $\mathrm{BIOT}_{4 \mathrm{PI}}$ showed lower values of area under the curve of daily parasitemia $\left(\mathrm{BIOT}_{\mathrm{PI}} \mathrm{p}<0.01\right.$ and $\left.\mathrm{BIOT}_{4 \mathrm{PI}} \mathrm{p}<0.01\right)$, lower total parasitemia $\left(\mathrm{BIOT}_{\mathrm{PI}}\right.$ $\mathrm{p}<0.01$ and $\mathrm{BIOT}_{4 \mathrm{PI}} \mathrm{p}<0.01$ ), and lower maximum peaks of parasites $\left(\mathrm{BIOT}_{\text {PI }} \mathrm{p}<0.01\right.$ and $\left.\mathrm{BIOT}_{4 \mathrm{PI}} \mathrm{p}<0.01\right)$ (Table 1). There was no statistical difference in parasitemia on the $8^{\text {th }}$ day of infection and in the $2^{\text {nd }}$ peak of parasites for the $\mathrm{BIOT}_{\mathrm{PI}}$ and $\mathrm{BIOT}_{4 \mathrm{PI}}$ groups compared to the control, as well as in the percentage of animals that showed the $2^{\text {nd }}$ maximum peak of parasites. These are characteristics typical of infection by the T. cruzi-Y strain: a peak of parasites on the $8^{\text {th }}$ day of infection and a second, lower peak of parasites, later. This second peak occurred earlier in $\mathrm{BIOT}_{\mathrm{PI}}$ and $\mathrm{BIOT}_{4 \mathrm{PI}}$ than in the control group. Considering the parameters shown in Table 2, compared to the control group, the $\mathrm{BIOT}_{\mathrm{PI}}$ and mainly $\mathrm{BIOT}_{4 \mathrm{PI}}$ groups showed longer prepatent periods $\left(\mathrm{BIOT}_{4 \mathrm{PI}} \mathrm{p}<0.01\right.$ and $\left.\mathrm{BIOT}_{\mathrm{PI}} \mathrm{p}=0.13\right)$ and shorter patent periods $\left(\mathrm{BIOT}_{\mathrm{PI}} \mathrm{p}<0.01\right.$ and $\mathrm{BIOT}_{4 \mathrm{PI}} \mathrm{p}<0.01$ ), longer survival times, significant for the $\mathrm{BIOT}_{4 \mathrm{PI}}$ group $(\mathrm{p}<0.01)$ and a lower (although not significantly lower) mortality. Together, these results show a better outcome of the infection, since the parasitemia in infection by $T$. cruzi is directly proportional to morbidity [17].

In contrast, the $\mathrm{BIOT}_{4-5-6}$ and $\mathrm{BIOT}_{7-8-9}$ groups showed a worse evolution of the infection compared to the control group. The area under the curve of daily parasitemia in these groups did not differ from the value observed for the control group $(\mathrm{p}=0.99)$, and similarly for total parasitemia $(\mathrm{p}=0.99)$. The $\mathrm{BIOT}_{4-5-6}$ and $\mathrm{BIOT}_{7-8-9}$ groups showed a higher maximum peak of parasites, significantly higher in the $\mathrm{BIOT}_{4-5-6}$ group, as well as a significant advancement of this maximum peak $(\mathrm{p}<0.01)$. There was no significant difference in the parasitemia peak on the $8^{\text {th }}$ day of infection, the parasitemia of the $2^{\text {nd }}$ peak of parasites, nor in the percentage of animals that showed the $2^{\text {nd }}$ peak for the $\mathrm{BIOT}_{4-5-6}$ and $\mathrm{BIOT}_{7-8-9}$ groups compared to the control group. The prepatent period and survival was lower for these 
Table 1 Parasitological parameters of animals subjected to different treatment schemes using biotherapic (BIOT $\left.{ }_{T c 17 \mathrm{dH}}\right)$

\begin{tabular}{|c|c|c|c|c|c|c|c|c|}
\hline GROUP & AUC $\left(\times 10^{5}\right)$ & $P_{\text {total }}\left(x 10^{6}\right)$ & $P_{\max }\left(x 10^{6}\right)$ & DAY OF $P_{\max }$ & $P_{8 \text { thDI }}\left(x 10^{6}\right)$ & $2^{\text {nd }} P_{\max }\left(x 10^{4}\right)$ & DAY OF $2^{\text {nd }}$ PEAK & $2^{\text {nd }}$ PEAK n/N (\%) \\
\hline $\mathrm{Cl}$ & $10.9 \pm 8.20$ & $12.5 \pm 8.98$ & $5.02 \pm 7.07$ & $10.76 \pm 3.15$ & $2.82 \pm 3.12$ & $11.0 \pm 10.2$ & $14.03 \pm 2.63$ & $8 / 12(66 \%)$ \\
\hline $\mathrm{BIOT}_{4-5-6}$ & $9.23 \pm 3.26$ & $9.33 \pm 3.25$ & $5.82 \pm 2.14^{* *}$ & $8.25 \pm 0.67^{* *}$ & $5.11 \pm 2.62$ & $2.10 \pm 17.4$ & $12.0 \pm 2.0^{*}$ & $4 / 12(33 \%)$ \\
\hline $\mathrm{BIOT}_{7-8-9}$ & $8.78 \pm 2.34$ & $9.32 \pm 2.48$ & $4.05 \pm 2.42$ & $8.64 \pm 0.71^{* *}$ & $3.96 \pm 2.51$ & $17.4 \pm 0$ & $14.25 \pm 1.02$ & $8 / 12(66 \%)$ \\
\hline BIOT $_{P \mid}$ & $5.95 \pm 4.55^{* *}$ & $6.63 \pm 5.02^{* *}$ & $2.25 \pm 1.65^{* *}$ & $15.46 \pm 23.06$ & $1.62 \pm 1.69$ & $11.1 \pm 13.6$ & $13.67 \pm 0.63^{*}$ & $6 / 12(50 \%)$ \\
\hline $\mathrm{BlOT}_{4 \mathrm{PI}}$ & $4.28 \pm 2.89^{* *}$ & $4.63 \pm 3.19^{* *}$ & $1.45 \pm 1.00^{* *}$ & $10.27 \pm 2.03$ & $1.01 \pm 0.96$ & $7.09 \pm 10.2$ & $12.8 \pm 0.68^{*}$ & $6 / 12(50 \%)$ \\
\hline
\end{tabular}

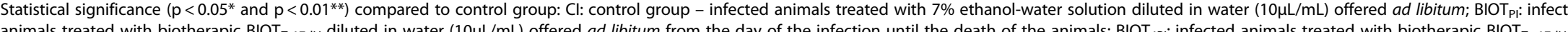
diluted in water $(10 \mu \mathrm{L} / \mathrm{mL})$ offered ad libitum from the $4^{\text {th }}$ day of the infection until the death of the animals; BIOT B $_{4-56}$ : infected animals treated with biotherapic BIOT

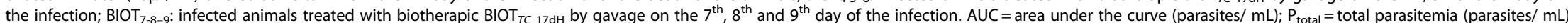
$\mathrm{P}_{\max }=$ maximum peak of parasites (parasites $/ \mathrm{mL}$ ); Day of $\mathrm{P}_{\max }=$ Day of maximum peak of parasites; $\mathrm{P}_{8 \text { thD }}=$ number of tripomastigotes on $8^{\text {th }}$ day of infection (parasites $/ \mathrm{mL}$ ); $2^{\text {nd }} \mathrm{P}_{\max }=$ number of tripomastigotes in

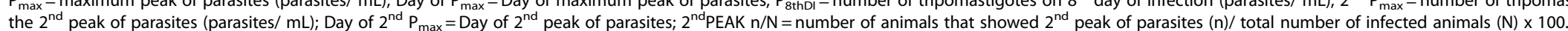


Table 2 Prepatent period (PPP), patent period (PP), survival and percent mortality of animals subjected to different treatment schemes using biotherapic (BIOT $\left._{T C 17 \mathrm{dH}}\right)$

\begin{tabular}{lcccc}
\hline GROUP & PPP (days) & PP (days) & SURVIVAL (days) & DEATH n/N (\%) \\
\hline $\mathrm{Cl}$ & $6.02 \pm 1.85$ & $9.63 \pm 2.74$ & $15.33 \pm 3.39$ & $12 / 12(100 \%)$ \\
BIOT $_{4-5-6}$ & $3.86 \pm 1.36^{*}$ & $7.43 \pm 1.99^{*}$ & $12.14 \pm 1.25^{*}$ & $12 / 12(100 \%)$ \\
BlOT $_{7-8-9}$ & $4.38 \pm 1.32^{*}$ & $8.88 \pm 1.62$ & $14 \pm 1.5$ & $12 / 12(100 \%)$ \\
BIOT $_{\text {PI }}$ & $13.67 \pm 33.11$ & $6.61 \pm 2.69^{* *}$ & $29 \pm 42.79$ & $10 / 12(83 \%)$ \\
BIOT $_{4 P \mid}$ & $21.5 \pm 42.87^{* *}$ & $5.78 \pm 1.03^{* *}$ & $27.1 \pm 40.98^{* *}$ & $11 / 12(92 \%)$
\end{tabular}

Statistical significance $\left(p<0.05^{*}\right.$ and $\left.p<0.01^{* *}\right)$ compared to control group: $\mathrm{Cl}$ : control group - infected animals treated with $7 \%$ ethanol-water solution diluted in water $(10 \mu \mathrm{L} / \mathrm{mL})$ offered ad libitum; $\mathrm{BIOT}_{\mathrm{PI}}$ : infected animals treated with biotherapic BIOT ${ }_{T c 17 \mathrm{dH}}$ diluted in water $(10 \mu \mathrm{L} / \mathrm{mL})$ offered ad libitum from the day of the infection until the death of the animals; BIOT $_{4 \mathrm{P}}$ : infected animals treated with biotherapic BIOT $T_{c} 17 \mathrm{dH}$ diluted in water $(10 \mu \mathrm{L} / \mathrm{mL})$ offered ad libitum from the $4^{\text {th }}$ day of the infection until the death of the animals; $\mathrm{BIOT}_{4-5-6}$ : infected animals treated with biotherapic BIOT $T \mathrm{CC} 17 \mathrm{dH}$ by gavage on the $4^{\text {th }}, 5^{\text {th }}$ and $6^{\text {th }}$ day of the infection; BIOT $7-8-9$ : infected animals treated with biotherapic BIOT $T C 17 \mathrm{dH}$ by gavage on the $7^{\text {th }}, 8^{\text {th }}$ and $9^{\text {th }}$ day of the infection.

groups compared to the control. Mortality was $100 \%$ of the animals, as also observed for the control (Table 2).

Considering the 12 parameters shown in Tables 1 and 2, the $\mathrm{BIOT}_{4 \mathrm{PI}}$ group showed the best overall performance.

In this study, the data obtained for the animals treated with highly diluted medications in the more appropriate treatment schemes $\left(\mathrm{BIOT}_{\mathrm{PI}}\right.$ and $\mathrm{BIOT}_{4 \mathrm{PI}}$ ) showed better results than those observed in the control group. Notably, in the $\mathrm{BIOT}_{\mathrm{PI}}$ and $\mathrm{BIOT}_{4 \mathrm{PI}}$ groups (which showed better evolution of the infection) there was a significant individual variation observed among the animals of the same group, as shown by the standard deviations (Tables 1 and 2). This individual variation was also observed in the control group.

These data suggest that some animals naturally evolve with lower parasitemia levels, while other animals evolve with higher parasitemia levels. The moreappropriate treatment schemes using highly diluted medications seemed to favor those animals with a tendency to develop lower parasitemia levels. This phenomenon may have led to the result in which the treatment of the $\mathrm{BIOT}_{4 \mathrm{PI}}$ or $\mathrm{BIOT}_{\mathrm{PI}}$ groups produced a decrease in the parasitemia levels and a tendency to a lower mortality level with a longer survival period. This contrasts with the study by Sandri et al. (2010) [18], where a different treatment scheme was used in the same experimental conditions.

\section{Clinical parameters}

The groups of animals that were given the medication $\left(\mathrm{BIOT}_{T c 17 \mathrm{dH}}\right)$ in water ad libitum for a long period showed better clinical evolution, with a stable body temperature $(\mathrm{p}<0.05)$, higher weight gain $(\mathrm{p}<0.01)$ and higher water consumption $(\mathrm{p}<0.05)$ compared to the control group. The groups treated for a long period $\left(\mathrm{BIOT}_{\mathrm{PI}}\right.$ and $\left.\mathrm{BIOT}_{4 \mathrm{PI}}\right)$ contained more animals with 'normal-looking' fur for longer periods during the study, and the $\mathrm{BIOT}_{4 \mathrm{PI}}$ group showed the best results of all. In the $\mathrm{BIOT}_{4-5-6}$ and $\mathrm{BIOT}_{7-8-9}$ groups, more animals showed bristling hair, with a similar evolution to the control group (CI).

In murine T. cruzi infection, the morbidity is linked to parasitemia [17]. However, the host-parasite relationship is essential for the manifestation of the disease, which appears more lethal when the balance of this relationship is jeopardized.

The functional recovery of complex biological systems occurs in an integrated manner (considering the psycho-neuro-immuno-endocrine-metabolic axis), and sometimes the imbalance of one part is necessary to maintain the balance as a whole, with the appearance of new signs and/or exacerbating old symptoms or manifestations [19].

In this context, the host immune response causes many symptoms of the infection [20,21], and may help to explain the discrepancy between virulence and parasite loads [22,23], suggesting new prospects for the advancement of these studies.

\section{Survival evaluation}

Three animals survived in the groups that were given the medication $\left(\mathrm{BIOT}_{T c 17 \mathrm{dH}}\right)$ in water ad libitum for a long period. Of these three survivors, two were from the BIOT $_{P I}$ group, and only one of them had patent parasitemia. The other had negative PCR (Polymerase Chain Reaction) [24], understood as a protective action of the drug, since the treatment began at the time of the infection. Considering that the T. cruzi-Y strain shows $100 \%$ infectivity and mortality in Swiss mice [12,25-27] this result shows a patent benefit of the medication.

The surviving animal in the $\mathrm{BIOT}_{4 \mathrm{PI}}$ group, although it showed a positive PCR diagnosis, never showed patent parasitemia. This result is consistent with low levels of parasitemia and provides information about the benefit of the treatment scheme used, since survival in the murine model is directly related to parasitemia levels [27].

The better evolution of the infection, considering both parasitological and clinical parameters in $\mathrm{BIOT}_{\mathrm{PI}}$ and mainly in $\mathrm{BIOT}_{4 \mathrm{PI}}$ is expressed by the delayed onset of mortality ( $16^{\text {th }}$ and $13^{\text {th }}$ day of infection, respectively) as well as the lower mortality compared to the control group. The survival of 3 animals for more than 360 days, with a mean and standard deviation of $27.1 \pm 40.98$ $(\mathrm{p}<0.01)$ and $29.0 \pm 42.79(\mathrm{p}>0.05)$ for the $\mathrm{BIOT}_{4 \mathrm{PI}}$ and BIOT $_{\mathrm{PI}}$ groups (Table 2), respectively, suggests an improved prognosis in a pathogenesis process that shows an irreversible evolution [28]. 


\section{Correlation analysis}

The correlation analysis indicates the relationship between two variables within a group. The relationships between each clinical or parasitological parameter (variable) and survival for the groups $\mathrm{CI}, \mathrm{BIOT}_{\mathrm{PI}}$ and $\mathrm{BIOT}_{4 \mathrm{PI}}$ were evaluated separately. This relation is expressed by a number called correlation coefficient (' $r$ '), which can be significant or not. Their values range from +1 to -1 , and its size indicates the force of correlation. Correlations up to 0.299 were considered weak, values from $0.300-0.499$ were considered intermediate, and strong from $0.500-0.999$. The signal indicates the direction, if the correlation is positive (direct) or negative (inverse).

Considering that in this model, the evolution of the disease is irreversible, culminating in the death of the animals, an increase in the survival period is an indicator of a good treatment scheme. Some clinical and / or parasitological parameters may be more or less related to this increase in survival. The correlation analysis may indicate which are the more important parameters that could be measured. Therefore, we evaluated the correlations between the parasitological/clinical parameters and survival periods for the control group (CI) and the groups treated with the biotherapic $\left(\mathrm{BIOT}_{T c 17 \mathrm{dH}}\right)$ in the treatment schemes that improved the clinical and parasitological evolution BIOT $_{\mathrm{PI}}$ and BIOT $_{4 \mathrm{PI}}$ ) (Table 3).

\begin{tabular}{|c|c|c|c|}
\hline \multicolumn{4}{|c|}{ 'r' FOR CORRELATION } \\
\hline PARAMETERS & $\mathrm{Cl}$ & $\mathrm{BIOT}_{\mathrm{PI}}$ & $\mathrm{BIOT}_{4 \mathrm{PI}}$ \\
\hline AUC & $(-) 0.2250$ & $(-) 0.1980$ & $(-) 0.2349$ \\
\hline$P_{\text {total }}$ & $(-) 0.3220$ & $(-) 0.4387$ & $(-) 0.5227$ \\
\hline$P_{\max }$ & $(-) 0.2989$ & $(-) 0.3182$ & $(-) 0.5350$ \\
\hline Day $P_{\max }$ & NS & NS & NS \\
\hline PPP & $(+) 0.4825$ & $(+) 0.6704$ & $(+) 0.9995$ \\
\hline PP & $(+) 0.7901$ & $(-) 0.7000$ & $(-) 0.8998$ \\
\hline $\mathrm{T}^{\mathrm{a}}$ & NS & NS & NS \\
\hline WEIGHT & NS & NS & $(+) 0.4797$ \\
\hline WATER & NS & NS & NS \\
\hline
\end{tabular}

$\mathrm{NS}=$ no significant correlation. ' $r$ ' values are presented for significant correlations $(p<0.05)$ between survival and the parameters: $A U C=$ area under the curve (parasites $/ \mathrm{mL}$ ); $P_{\text {total }}$ - total parasitemia (parasites $/ \mathrm{mL}$ )

$P_{\max }=$ maximum peak of parasites (parasites/ $\mathrm{mL}$ ); Day of $\mathrm{P}_{\max }$ - Day of maximum peak of parasites; $P P P=$ Prepatent period; $P P=$ patent period; $\mathrm{T}^{\mathrm{a}}=$ Temperature; Weight and Water. Groups: Cl: control group - infected animals treated with $7 \%$ ethanol-water solution diluted in water $(10 \mu \mathrm{L} / \mathrm{mL})$ offered ad libitum; $\mathrm{BIOT}_{\mathrm{PI}}$ infected animals treated with biotherapic BIOT ${ }_{T \mathrm{C} 17 \mathrm{dH}}$ diluted in water $(10 \mu \mathrm{L} / \mathrm{mL})$ offered ad libitum from the day of the infection until the death of the animals; BIOT4PI: infected animals treated with biotherapic BIOT ${ }_{T c 17 \mathrm{dH}}$ diluted in water $(10 \mu \mathrm{L} / \mathrm{mL})$ offered ad libitum from the $4^{\text {th }}$ day of the infection until the death of the animals.
The prepatent period (PPP), patent period (PP) and total parasitemia $\left(\mathrm{P}_{\text {total }}\right)$ showed moderate to strong correlations with the survival period for all groups. For shorter survival periods, the groups showed higher total parasitemia $\left(\mathrm{P}_{\text {total }}\right)$. In groups treated for a long period, the $\mathrm{P}_{\text {total }}$ was lower and showed increasing ' $\mathrm{r}$ ' values $\left(\mathrm{BIOT}_{4 \mathrm{PI}}>\mathrm{BIOT}_{\mathrm{PI}}>\mathrm{CI}\right)$.

The prepatent period (PPP) was best correlated with the survival period. The $\mathrm{BIOT}_{4 \mathrm{PI}}$ group showed a strong and positive correlation $(r=0.9995)$, indicating that the survival was closely linked to an increase in the prepatent period (PPP). In the different groups, this parameter clearly reflected the differences in performance under the different treatments, showing increasing ' $r$ ' values for the $\mathrm{BIOT}_{4 \mathrm{PI}}, \mathrm{BIOT}_{\mathrm{PI}}$ and $\mathrm{CI}$ groups. This result, combined with the set of data obtained in this study, indicated that the PPP was the best parameter to evaluate an intervention in this model.

This finding is important considering that in protocols with highly diluted substances, researchers tend to evaluate an excessive number of parameters in an attempt to include the key change that shows a benefit, since benefits may be perceived but cannot always be measured. In the experimental protocol used in this study, the risk of contamination and the workload involved need to be optimized, and it is imperative to select parameters that show the best effects most clearly.

The other parameters evaluated showed weak correlations with survival, although they also showed peculiarities in the comparison among the experimental groups. The maximum peak of parasites $\left(\mathrm{P}_{\max }\right)$ was inversely correlated with the survival period; the relationship was moderate for the $\mathrm{CI}$ and $\mathrm{BIOT}_{\mathrm{PI}}$ groups and strong for the $\mathrm{BIOT}_{4 \mathrm{PI}}$ group. These results concord with those for the treatment schemes that began after the fourth day of infection, and again indicate the importance of the treatment scheme in determining the degree of morbidity from the infection.

The correlation between the peak day and the survival period had a particular result: the correlation was strong and direct in the CI group, showing that the later the peak of parasites, the longer is the survival time. In the groups treated with the biotherapic, the correlation was strong, but negative, with a higher ' $r$ ' value for the group that performed best in this study $\left(\mathrm{BIOT}_{4 \mathrm{PI}}>\mathrm{BIOT}_{\mathrm{PI}}\right)$.

This fact is consistent with what we have observed in previous studies: the biotherapic medications seem to anticipate several important biological phenomena in the course of experimental infection with T. cruzi [29]. The high standard deviation observed for this parameter in the $\mathrm{BIOT}_{4 \mathrm{PI}}, \mathrm{BIOT}_{\mathrm{PI}}$ and $\mathrm{CI}$ groups indicates the individuality of behavior for this parameter (Table 2). Sandri et al. (2010) [18] has also observed this behavior individuality in both the treated and control group and 
found out that the animals that were more resistant to infection had a higher sensitivity to the treatment. In the case of Sandri et al. (2010) [18] the treatment scheme was inadequate and resulted in increased parasitemia.

These results show that some parameters can work as 'markers' of the performance of an intervention in the infection model used in this study, clearly reflecting the evolution of infection and these parameters can be prioritized in the experimental design, minimizing the work of researchers.

Although in this study in mice, the clinical parameters of temperature, weight and water consumption, as measured, were not effective to clarify the best therapeutic scheme using $\mathrm{BIOT}_{T c 17 \mathrm{dH}}$, the researcher perceive the difference among the groups. Find better methods to evaluate these parameters is an important perspective.

Considering the groups of animals treated for long periods, the $\mathrm{BIOT}_{4 \mathrm{PI}}$ group presented a better performance with an intermediate correlation between weight and survival. These data, besides reflecting more accurately what was observed in the clinical evaluations, also supports a good prognosis for animals treated with this scheme.

\section{Further discussions}

The differences observed when comparing the evolution of infection in the groups treated for a long period in water $\left(\mathrm{BIOT}_{\mathrm{PI}}\right.$ andBIOT $\left.4 \mathrm{PI}\right)$, and for a short period of time by gavage $\left(\mathrm{BIOT}_{4-5-6}\right.$ and $\mathrm{BIOT}_{7-8-9}$ ) show a better balance for animals treated for longer periods in water. The discussion of these results can also be based on the fact that the medication administered in water for a long period, besides enabling a higher number of stimuli, also causes less stress to the animal compared to the treatment by gavage, for a short period of time. Also in relation to medication administration, diluted in water, the difference in the intake among the animals, although it may be criticized, According to some authors, the concept of medication dose as the amount of medication that a patient must take to modify his state of illness is not applicable to highly diluted medications, because they do not act based on their mass, but rather by their dynamic effect (qualitative), which continues for a shorter or longer period according to the power of reaction or sensitivity of the organism and the stage of the disease [22,23].

Our data concord with the findings of other investigators that the use of highly diluted medications in the acute phase of infection requires a higher frequency of administered doses [23]. In a randomized controlled experiment, the benefit of the treatment using highly diluted medication continuously and for long periods of time, without interruption of the stimulus, promotes balance in acute infections [23].
Considering that the stimulation provided by the highly diluted medication is related to its ability to affect the psycho-neuro-immune-endocrine-metabolic axis, stress may also be a destabilizing factor that should be considered in evaluating the results [15].

T. cruzi is an obligate intracellular parasite and its interaction with the host cells is complex, and inflammation is a decisive component of the pathogenesis. In developing resistance to $T$. cruzi, the immune system can act through different routes that function more or less effectively, depending on the conditions imposed by the host-parasite relationship [17]. Sandri et al. (2011) [30] demonstrated modulation of the inflammation process in eight-week-old animals infected with T. cruzi and treated with a biotherapic, with a higher rate of apoptosis and reduced production of the cytokine transforming growth factor beta (TGF- $\beta$ ).

In the present study, assuming that the highly diluted medication $\mathrm{BIOT}_{T c 17 \mathrm{dH}}$ modulated the host immune system, the finding that the best therapeutic result was achieved with the medication administered beginning after 4 days of infection and for long periods (BIOT $4 \mathrm{PI})$ is consistent with the following hypothesis: In this scheme, the host's immune system, already activated by the parasite and affected by the highly diluted medication, leads the infection to evolve less aggressively, as described by Sandri et al. (2011) [30].

\section{Conclusion}

The $\mathrm{BIOT}_{4 \mathrm{DI}}$ group showed the best clinical and parasitological evolution, with lower parasitemia and a trend toward lower mortality with longer periods of survival. The PPP (prepatent period = time in days from the infection until the first parasite was detected in the blood) proved to be the best parameter to evaluate the effect of a medication in this model.

\section{Methods}

\section{Animals and infection}

The study involved 60, 28-day-old male Swiss mice from the Central Animal Facility of the Universidade Estadual de Maringá. The animals were infected intraperitoneally with 1,400 blood trypomastigotes of T. cruzi-Y strain [12].

\section{Groups according to treatment}

The animals were divided equally into five groups according to the treatment: CI - infected animals treated with $7 \%$ ethanol-water solution diluted in water $(10 \mu \mathrm{L} / \mathrm{mL})$ offered ad libitum in an amber bottle; $\mathrm{BIOT}_{\mathrm{PI}}$-infected animals treated with BIOT $_{T c 17 \mathrm{dH}}$ diluted in water $(10 \mu \mathrm{L} / \mathrm{mL})$ offered ad libitum in an amber bottle during a period that started on the day of infection and finished when the animals died; $\mathrm{BIOT}_{4 \mathrm{DI}}$ - infected animals treated with BIOT $_{T c 17 \mathrm{dH}}$ diluted in water $(10 \mu \mathrm{L} / \mathrm{mL})$ offered ad libitum 
in an amber bottle from the $4^{\text {th }}$ day of infection to the death of the animals; $\mathrm{BIOT}_{4-5-6}$ - infected animals treated with $\mathrm{BIOT}_{T c 17 \mathrm{dH}}$ administered by gavage $(0.2 \mathrm{~mL} /$ animal / day) on the $4^{\text {th }}, 5^{\text {th }}$ and $6^{\text {th }}$ days after infection; $\mathrm{BIOT}_{7-8-9}$ - infected animals treated with $\mathrm{BIOT}_{T c 17 \mathrm{dH}}$ administered by gavage $(0.2 \mathrm{~mL} /$ animal / day) on the $7^{\text {th }}, 8^{\text {th }}$ and $9^{\text {th }}$ days after infection.

The different treatment schemes were based on the effect of medication linked to the immunological effect $[3,18]$ and on the specific evolution of T. cruzi-Y strain in Swiss mice [12,27]. Thus, $\mathrm{BIOT}_{\mathrm{PI}}$ and $\mathrm{BIOT}_{4 \mathrm{PI}}$ simulated a situation where the medication is offered when the immunological system is not in contact with the parasite, and a situation where the medication is offered when the immunological system is already in contact with the parasite, respectively. In $\mathrm{BIOT}_{4-5-6}$ and $\mathrm{BIOT}_{7-8-9}$, the medication was offered to animals just prior to the parasite peak and exactly coincident with the parasite peak, respectively [12,27].

\section{Experimental design}

The experiment was performed twice as a blind randomized controlled trial. The animals were divided into separate cages so that the mean initial weights of mice in each group were statistically equal. The animals were kept in a climate-controlled vivarium, under controlled temperature $\left(22.7 \pm 1.2^{\circ} \mathrm{C}\right)$, light/dark cycles of 12 hours, and water and food offered ad libitum.

\section{Biotherapic T. cruzi $17 \mathrm{dH}$ (BIOT Tc17dH )}

The highly diluted medication was produced from the buffy coat of blood collected from the orbital plexus of three mice, containing blood trypomastigotes on the 7th day of infection with T. cruzi $Y$-strain. The BIOT $_{T c 17 \mathrm{dH}}$ was prepared by adding $0.9 \mathrm{~mL}$ of $T$. cruzi concentrate (4.1 x $10^{7}$ trypomastigotes $/ \mathrm{mL}$ ) in $9.1 \mathrm{~mL}$ of distilled water in a $30-\mathrm{mL}$ glass bottle. Subsequently, dilutions were made in a $70 \%$ ethanol-water solution until the $16 \mathrm{dH}$ dynamization. The dynamization used, $17 \mathrm{dH}$ (corresponding to a dilution of $1: 10^{17}$ of the initial suspension) was prepared with $7 \%$ ethanol-water solution. [8] The microbiological test and the biological risk in vivo were negative, according to the regulations of the Brazilian Ministry of Health (RDC No. 67) [31], and the drug was stored in amber glass for better conservation.

\section{Parameters analyzed}

Parasitological and clinical parameters were evaluated. Parasitemia was evaluated by daily counts of blood trypomastigotes from the day of infection, using the technique of Brener (1962) [32]. For animals that showed negative parasitemia, blood was collected for PCR diagnosis (Polymerase Chain Reaction) [24].
Using the parasitemia curve, the following data were obtained: prepatent period (PPP), which is the time from infection to detection of the parasite in blood; patent period (PP), the period when the parasitemia can be detected; and total parasitemia $\left(\mathrm{P}_{\text {total }}\right)$, calculated as the sum of the mean daily parasitemia levels for each mouse in each group. The area under the curve (AUC), defined as the number of parasites/ $\mathrm{mL}$ of blood observed at a certain time of infection, was calculated using the software Prism Graph 5. The peak of maximum parasitemia $\left(\mathrm{P}_{\max }\right)$, considered the mean of the highest level of parasitemia observed in each animal throughout the experiment, parasitemia on the $8^{\text {th }}$ day of infection, the $2^{\text {nd }}$ peak of parasites, and the percentage of occurrence of this $2^{\text {nd }}$ peak of parasites. The parasitemia was expressed in parasites/ $\mathrm{mL}$ and the occurrence of this $2^{\text {nd }}$ peak was expressed by the percentage of animals that showed a peak (n) within a group $(\mathrm{N})$. The day on which these peaks occurred was also considered. Mortality was computed during the course of the experiment, resulting in the following parameters: days of survival and percentage of mortality expressed by the number of animals died $(\mathrm{n})$ within a group $(\mathrm{N})$. The animals were clinically evaluated on alternate days from the day of infection until the end of the treatment for body temperature, water consumption, fur appearance, and body weight [33].

\section{Statistical analysis}

The results were compared statistically using the program Statistica 7.0, and the Kruskal-Wallis test (ANOVA followed by multiple comparisons of mean ranks for all groups) was used since the analyzed parameters did not all show a normal distribution. The correlations were analyzed using the R.2.10 program. Correlations with ' $r$ ' value up to 0.299 were considered weak, from $0.300-0.499$ as intermediate, and from $0.500-0.999$ as strong. The acceptable level of significance was $5 \%$ for all analyses.

\section{Ethics}

The experiment was approved by the Ethics Committee for Animal Experimentation at the Universidade Estadual de Maringá (UEM), under protocol number 030/2008.

\footnotetext{
Abbreviations

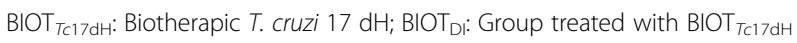
diluted in water offered ad libitum during a period that started on the day of infection and finished when the animals died; $\mathrm{BIOT}_{4 \mathrm{DI}}$ : Group treated with BIOT $_{T C 17 \mathrm{dH}}$ diluted in water offered ad libitum from the $4^{\text {th }}$ day of infection to the death of animals; $\mathrm{BIOT}_{4-5-6}$ : Group treated with BIOT TC17dH administered by gavage on $4^{\text {th }}, 5^{\text {th }}$ and $6^{\text {th }}$ days after infection; $\mathrm{BIOT}_{7-8-9}$ : Group treated with BIOT ${ }_{T c 17 d H}$ administered by gavage on $7^{\text {th }}, 8^{\text {th }}$ and $9^{\text {th }}$ days after infection; Cl: Control of infection; AUC: Area under the curve; $P_{\text {total }}$ : Total parasitemia; $P_{\max }$ : Maximum peak of parasites; Day of $P_{\max }$ : Day of maximum peak of parasites; $P_{8 \text { thD }}$ : Parasitemia of $8^{\text {th }}$ day of infection; $2^{\text {nd }} P_{\text {max }}$ : Second maximum peak of parasites; Day of $2^{\text {nd }} P_{\text {max }}$ : Day of $2^{\text {nd }}$ maximum peak of parasites; PPP: Pre patent period; PP: Patent period.
} 


\section{Competing interests}

The authors declare that they have no competing interests.

\section{Authors' contributions}

All authors are key members of the research consortium and have made substantial contributions to the conception and the design of the study, and acquisition of the baseline data. They have all been involved in writing the manuscript and have given their approval for the final version.

\section{Acknowledgments}

This work was supported by PROAP/ CAPES and Fundação Araucária- Paraná, Brazil.

\section{Author details}

${ }^{1}$ Laboratory of Parasitology, Universidade Estadual de Maringá, Maringá, PR, Brazil. 'Laboratory of Parasitology, Universidade Federal de Ouro Preto, Ouro Preto, MG, Brazil. ${ }^{3}$ Laboratory of Microbiology, Universidade Estadual de Maringá, Maringá, PR, Brazil.

Received: 14 March 2012 Accepted: 26 June 2012

Published: 11 July 2012

\section{Reference}

1. Lyrio C: Nosódios Bioterápicos: Repertório. Rio de Janeiro: C. Lyrio; 2002.

2. Bonamin LV: Teorias Interpretativas sobre ultradiluições: Ilustrações Experimentais. Cultura Homeopática 2006, 16:6-17.

3. Bellavite P, Ortolani R, Pontarollo F, Pitari G, Conforti A: Immunology and Homeopathy. 5. The Rationale of the 'Simile'. Evidence-Based Complementary and Alternative Medicine 2007, 4(2):149-163.

4. Sandri PF, Falkowski GJS, Nascimento Júnior AD, Spack M, Moreira NM, Toledo MJO, Abreu Filho B, Gabriel M, Araújo SM: Biotherapic of Trypanosoma cruzi $17 x$ controlled histopathological alterations in mice infected by this protozoon. International Journal of High Dilution Research 2011, 10(36):119-12.

5. Thompson EA: Homeopathy and menopause. J Br Menopause Soc 2002, 8(4):151-154.

6. Vetoshkina TV, Fomina TI: Effects of homeopathic preparations on the liver in rats with acute and chronic toxic hepatitis. Bull Exp Biol Med 2003, 135(1):85-87.

7. Brack A, Strube J, Stoltz P, Decker H: Effects of ultrahigh dilutions of 3,5-dichlorophenol on the luminescence of the bacterium Vibrio fischeri. Biochemical, Biophysical Acta 2003, 1621(3):253-260.

8. Brasília DF: Farmacopéia Homeopática Brasileira. 3rd edition. Brasília DF: Ed. Agência Nacional de Vigilância Sanitária (ANVISA); 2011.

9. Almeida LR: Efeitos de medicamentos Homeopáticos e Bioterápicos em Camundongos experimentalmente infectados por Trypanosoma evansi (STEEL, 1885) BALBIANI, 1988 e Trypanosoma cruzi CHAGAS, 1909. Seropédica: Tese Doutorado em Ciências Veterinárias - Instituto de Veterinária/ Universidade Federal Rural do Rio de Janeiro; 2007:68.

10. Bonamin LV, Lagache A, Bastide M: Research on Ultra-dilutions and the Theory of Corporeal Signifiers: The Follow Up. In Signals and Images: Contributions and contradictions about high dilution research. São Paulo: Bonamin LV: Ed. Springer; 2008.

11. Coura JR, Dias JC: Epidemiology, control and surveillance of Chagas disease - 100 years after its discovery. Memórias do Instituto Oswaldo Cruz 2009, 104(Suppl. I):31-40.

12. Silva LHP, Nussenzweig V: Sobre uma cepa de Trypanosoma cruzi altamente virulenta para o camundongo branco. Folia Clínica Biologia São Paulo 1953, 20:191-201.

13. Pinto PLS, Takami R, Nunes EV, Guilherme CS, Oliveira JOC, Gama-Rodrigues J, Okumura M: Life cycle of Trypanosoma cruzi (y strain) in mice. Revista do Hospital das Clínicas 1999, 54:141-146.

14. Coura JR, Castro SL: A critical review on Chagas Disease Chemotherapy. Memórias do Instituto Oswaldo Cruz 2002, 97(1):3-24.

15. Higuchi MD: Endomyocardial biopsy in Chagas' heart disease: pathogenetic contributions. Sao Paulo Med J 1995, 113:821-825.

16. Tafuri WL: Patogenia da doença de chagas. Rev Inst Med Trop São Paulo 1987, 29(4):194-199.

17. Desquesnes M, Lana M: Veterinary Aspects and Experimental Studies. In American Trypanosomiasis Chagas Disease: one hundread year of research. Edited by Telleria J, Tibayrenc M. London: Elsevier Inc.; 2010.
18. Sandri PF: Influência da idade sobre os efeitos do bioterápico $17 \mathrm{dH}$ na infecção de camundongos pelo Trypanosoma cruzi. Dissertação (Mestrado em Biociências Aplicada a Farmácia). São Paulo, SP: Universidade Estadual de Maringá; 2010:79.

19. Teixeira MZ: Possíveis contribuições do modelo homeopático à humanização da formação médica. Revista Brasileira de Educação Médica 2009, 33:454-463.

20. Dodoo D, Omer FM, Todd J, Akanmori BD, Koram KA, Riley EM: Absolute levels and ratios of proinflammatory and anti-inflammatory cytokine production in vitro predict clinical immunity to Plasmodium falciparum malaria. Journal of Infectious Disease 2002, 185(7):971-979.

21. Clark IA, Alleva LM, Mills AC, Cowden WB: Pathogenesis of malaria and clinically similar conditions. Clin Microbiol Rev 2004, 17(3):509-539.

22. Jones TR, Narum DL, Gozalo AS, Aguiar J, Fuhrmann SR, Liang H, Haynes JD, Moch JK, Lucas C, Luu T: Protection of Aotus monkeys by Plasmodium falciparum EBA-175 region II DNA prime-protein boost immunization regimen. Journal of Infectious Disease. 2001, 183(2):303-312.

23. Wickramasinghe SN, Abdalla SH: Blood and bone marrow changes in malaria. Baillieres Best Practice and Research Clinical Haematology 2000, 13(2):277-299.

24. Claudia TM, Mônica LG, Aline VM, Silvana MA, Maria TB, Olindo AM, Marta L, Max JOT: Usefulness of the polymerase chain reaction for monitoring cure of mice infected with different Trypanosoma cruzi clonal genotypes following treatment with benznidazole. Exp Parasitol 2008, 120(1):45-49.

25. Telleria J, Tibayrenc M: American Trypanosomiasis Chagas Disease: one hundread year of research. London: Elsevier Inc; 2010.

26. Araújo-Jorge TC: Modelos experimentais para o estudo in vivo da doença de Chagas: Camundongo. In Doença de Chagas: Manual de experimentação animal. Fiocruz:; 2000.

27. Ferraz FN, Simoni GK, Nascimento AD, Melo CS, Aleixo DL, Gomes ML, Spaki M, Araújo SM: Different forms of administration of biotherapy $7 \mathrm{dH}$ in mice experimentally infected by Trypanosoma cruzi produce different effects. Homeopathy 2011, 100:237-243.

28. Carvalheiro JR, Collares EF: Estudos sobre o comportamento em camundongos de uma amostra altamente virulenta de Trypanosoma cruzi (Amostra Y), após passagem em triatomíneos, ratos e culturas. Rev Bras Biol 1965, 25:169-75.

29. Billotti C, Ferraz FN, Spack M, Nascimento Júnior AD, Panza S, Alvares AA, Gomes ML, Toledo MJ, Martinichen JC, Araújo SM: Parâmetros hematológicos em camundongos infectados pelo Trypanosoma cruzi e tratados com bioterápicos. Brazilian Homeopathic Journal 2009, 11:9-10.

30. Sandri PF, Falkowski GJS, Hernandes L, Dalalio MO, Aleixo DL, Gomes ML, Anélio DN, Moliterno RA, Araujo SM: Biotherapic of Trypanosoma cruzi 17d increases apoptosis in experimentally infected mice. Proceedings of the XXV GIRI Symposium and VIII CBFH on International Journal of High Dilution Research 2011, 2011:119-124.

31. BRASIL Ministério da Saúde: RESOLUÇÃO DA DIRETORIA COLEGIADA - RDC $N^{\circ}$ 67. Diário Oficial da União, Brasília (DF): Diário Oficial da União, Brasília (DF); 2007. 8 de outubro de 2007.

32. Brener Z: Therapeutic activity and criterion of cure on mice experimentally infected with Trypanosoma cruzi. Rev Inst Med Trop São Paulo 1962, 4:189-196.

33. Silva DR, Castro SL, Alves MCS, Batista WS, Oliveira GM: Acute experimental Trypanosoma cruzi infection: establishing a murine model that utilizes non-invasive measurements of disease parameters. Memórias do Instituto Oswaldo Cruz 2012, 107(2):211-216.

doi:10.1186/1756-0500-5-352

Cite this article as: Aleixo et al:: Highly diluted medication reduces parasitemia and improves experimental infection evolution by Trypanosoma cruzi. BMC Research Notes 2012 5:352. 